\title{
Use of leaf thickness sensors in horticultural crops
}

\author{
F.S. Lauriks, H.A.L. Van de Put, D.J.W. De Pauw and K. Steppe \\ Laboratory of Plant Ecology, Department of Applied Ecology and Environmental Biology, \\ Faculty of Bioscience Engineering, Ghent University, Coupure Links 653, 9000 Ghent, Belgium \\ Fran.Lauriks@UGent.be
}

\begin{abstract}
Changes in leaf thickness can be a rapid indicator of the plant's water status and can therefore serve as an alarm signal for potential water deficits. Combining the use of continuous leaf thickness measurements with a mechanistic plant model describing optimal leaf growth and diel variations, would allow growers to optimize greenhouse growing conditions by adaptation of the microclimate and applied irrigation. Recent development of new sensors offers the possibility for real time measurements of leaf thickness on small plants, including ornamentals. However, the accuracy of leaf thickness variation measurements needs to be assured. In this study, the temperature influence on 12 LeafSen (Netafim, Tel Aviv, Israel) sensors has been tested in a temperature range from $16{ }^{\circ} \mathrm{C}$ to $31{ }^{\circ} \mathrm{C}$ by installation of the sensors on aluminium plates. Temperature variations in the investigated range resulted in sensor signal differences of up to $48 \mu \mathrm{m}$, indicating that temperature response can exceed the expected diel leaf thickness variation. Two typical temperature responses were distinguished, pointing to the need for a sensor specific temperature correction. The practical use of leaf thickness sensors and the established temperature corrections has been demonstrated by installing the sensors on the stem and leaf of three Ficus plants (Ficus benjamina) and three pot roses (Rosa chinensis cv.) starting from cutting stage in a commercial greenhouse environment.
\end{abstract}

Keywords: ornamental horticulture, temperature correction, water deficit, plant water status, water relations

\section{INTRODUCTION}

The use of plant-based measurements has for long been proposed as a highly sensitive way to detect drought stress and a potential reliable irrigation regulator (Jones, 2004). However, the assessment of plant water status often requires labour intensive measurements (e.g. pressure chamber) or sophisticated and often also expensive equipment (e.g. psychrometer, fruit/stem diameter measurements) (Jones, 2004). Furthermore, these techniques only indicate plant drought stress after calibration, determination of threshold values and have trouble determining the amount of water needed. Steppe et al. (2008) proposed an alternative technique for irrigation scheduling, combining the use of continuous plant-based measurements with plant modelling. The combination of continuous sap flow and stem diameter variation measurements with mathematical modelling allow to determine if and when irrigation is needed and the amount of water that should be applied (Steppe et al., 2008). Expansion of this model allows simulating leaf thickness.

In analogy to stem diameter, leaf thickness shows diel variations related to ambient air temperature and humidity (Meidner, 1952; Búrquez, 1987). Previous research has indicated that leaf thickness can serve as an indicator of the plant's water status (Bachmann, 1922; Búrquez, 1987; Jones, 2004) and can be used for irrigation regulation (Sharon et al., 2001; Pardossi and Incrocci, 2011; Cirillo et al., 2013). Previously, leaf thickness was measured continuously with the use of differential transducers (e.g. Heilman et al., 1968; Kadoya, 1978; Syvertsen and Levy, 1982; Malone, 1992; Else et al., 1995), also often applied for stem diameter measurements. However, the use of these sensors has been limited in commercial greenhouses due to their size, weight and required skill for installation (Seelig et al., 2011). The development of a new small and light leaf thickness sensor with straightforward installation overcomes these problems (Seelig et al., 2011). The use of these new sensors in combination with an expansion of 
the model introduced by Steppe et al. (2006) and De Swaef and Steppe (2010) therefore offers an opportunity towards efficient plant-based irrigation scheduling.

In 1996, Sharon and Bravdo introduced the LeafSen sensors (LeafSen, Netafim, Tel Aviv, Israel) as a first alternate leaf-sensing device (Sharon and Bravdo, 1996). Its measuring principle exists of a stainless steel sensing tongue with a strain gauge connected to a Wheatstone bridge (Sharon and Bravdo, 2001). In 2010, the SG-1000 (SG-1000, Agrihouse Inc., Berthoud, CO, USA) sensor was presented, measuring leaf thickness variations using electrical distance transducers. In previous research, LeafSen has successfully been used for drought stress detection and irrigation scheduling on commercial citrus, advocado and cotton plots, resulting in a reduction of total water application up to $30 \%$ (Sharon and Bravdo, 2001). Moreover, De Swaef et al. (2012) and Vanhassel et al. (2014) used the LeafSen thickness sensor in their research on tipburn in lettuce. The SG-1000 has been successfully installed on cowpea plants, where a reduction of irrigation water up to $45 \%$ could be realized (Seelig et al., 2011).

In this research, the application of the LeafSen sensors for measuring leaf thickness variation on two ornamental crops, Ficus benjamina and Rosa chinensis cv., was investigated. Furthermore, the possibility of simulating the leaf thickness variation, by extending the existing plant model of Steppe et al. (2006) and De Swaef and Steppe (2010), was tested. However, during data collection contradictory and unexpected physiological patterns were obtained. Before data implementation in the extended model, possible additional influences on the LeafSen signal were inspected. Consequently, an experiment was conducted where the influence of temperature variations on the LeafSen sensors was verified. By installing the thickness sensors on aluminium plates at varying temperatures, the temperature response could be established and a correction curve was created. Only after correction, the data could be used in the extended leaf thickness model.

\section{MATERIALS AND METHODS}

\section{Establishing temperature correction curves on aluminium plates}

In this research the temperature influence on twelve LeafSen (LeafSen, Netafim, Tel Aviv, Israel) sensors (LS 1-12) was investigated. These sensors were selected because of their small size (length $38 \mathrm{~mm}$; width $16 \mathrm{~mm}$ ) and weight ( $2.43 \mathrm{~g}$ ) and easy installation procedure, making them highly applicable in commercial greenhouses. During all experiments, air temperature was measured using a Campbell CS215 temperature and relative humidity sensor (Campbell Scientific, Logan, UT, USA). Temperature dependence was determined by installing the LSsensors on an aluminium plate of $0.5 \mathrm{~mm}$ thickness for 4 days in greenhouse conditions. Air temperature changed from $16^{\circ} \mathrm{C}$ to $31^{\circ} \mathrm{C}$.

\section{Measurements on ornamental crops}

The relationship between temperature and LeafSen variation was used to correct leaf and stem thickness data of pot roses (Rosa chinensis cv.) and Ficus benjamina plants. Starting from March $26^{\text {th }} 2016$, these plants were grown from cutting stage. Both roses and Ficus plants were grown on a mixed substrate (respectively, Pindstrup and Peltracom). Cultivation of both ornamentals took place in experimental greenhouses $\left(90 \mathrm{~m}^{2}\right)$ at PCS, Ornamental Plant Research Centre, in Destelbergen, Belgium. Climate control and growing conditions were comparable with commercial greenhouses. Plants were irrigated with an automatic flood irrigation system, based on time and solar radiation. Incoming radiation was controlled with thermal screens and extra assimilation lightning was provided for the roses. Also heating, including root heating for the Ficus plants, and $\mathrm{CO}_{2}$-control were used.

From 26 to 29 May 2016, leaf and stem thickness variations of three Ficus benjamina and three Rosa chinensis cv. plants were continuously monitored with a LeafSen sensor. Sensors were installed on thinner stem segments within the sensor's calibration range (diameter $<2$ $\mathrm{mm}$ ). Measured leaves were selected to describe average mature leaf growing patterns. To this end, young green leaves at the top and old dark green leaves at the bottom of the plant were 
avoided. Temperature during the plant-based measurements changed between $20^{\circ} \mathrm{C}$ and $28{ }^{\circ} \mathrm{C}$ in the rose greenhouse and between $18{ }^{\circ} \mathrm{C}$ and $33^{\circ} \mathrm{C}$ in the Ficus greenhouse.

\section{RESULTS AND DISCUSSION}

\section{Temperature response curves}

Maximal theoretical thickness variation of the aluminium plate in the exposed temperature range equalled $0.35 \mu \mathrm{m}\left(\alpha=23.110^{-6} \mathrm{~K}^{-1}\right.$ at $\left.20^{\circ} \mathrm{C}\right)$. Since minimal registered variations by the LeafSen sensors installed on the aluminium plates far exceeded these theoretical variations, the plate was assumed to be of constant thickness.

A linear relation between temperature and collected LeafSen measurements on the aluminium plate was established for all LeafSen sensors. As shown in Fig. 1 two typical relationships could be distinguished between temperature and LS-data. Type 1 sensors, described by the typical example LS1, show a clear relation between variation in temperature and the thickness sensor. Within this category a great variety of relationships were observed with both increasing and decreasing LS-signals with increasing temperature. Type 2 sensors, represented by LS2, show almost no overall variation with changing temperature. The existence of different types of correction curves and the variability within a category indicates that a sensor specific correction curve needs to be established and prevents the development of a general correction applicable for all sensors.

As shown in Fig. 1, both type 1 and 2 sensors show the presence of clock-wise hysteresis in LS-signalling in response to air temperature. For LS2, the hysteresis results in a $5 \mu \mathrm{m}$ difference between measured LS-signal and linear approximation, for both increasing and decreasing temperatures. A second order equation describing sensor output with increasing and decreasing temperature separately would allow improved approximation but would thereby preclude an easy and fast temperature correction. LS1 measurements show a drift in slope on two consecutive days. It is possible that the increased temperature range on the second day of measurements had an influence on the hysteresis shape and therefore on the calculated slope. However, the determined linear relation succeeds to describe the overall temperature dependence. Future repetition of the experiment will allow validation of the established linear relation and the corresponding slope over time and a varying daily temperature range.

Previous research of Syvertsen and Levy (1982) on citrus trees and Else et al. (1995) on tomato using a displacement transducer indicated that leaf thickness could vary $30-35 \mu \mathrm{m}$ daily. However, when installed on an aluminium plate, variations in data output up to $48 \mu \mathrm{m}$ were measured when undergoing a temperature change of $14{ }^{\circ} \mathrm{C}$ (Fig. 1). Consequently, patterns described by raw, non-corrected LS data can be strongly influenced by ambient temperature changes. This can result in an amplification, counteraction or even reversal of the physiological leaf thickness pattern due to temperature variations.

Since the scope of the temperature correction consists of determining the variation in LeafSen output as a result of temperature variation, only the slope of the established curve was used for temperature correction. As a result, the significance of obtained absolute thickness values is negligible. Fig. 2 compares the actual variations in LeafSen signals with its predicted values for LS1 using the equation's slope. Even though the simulation is not perfect, a linear equation seems able to approximate the signal variations of the LeafSen sensors caused by variations in temperature.

\section{Correction of ornamental crop data}

In Fig. 3, two non-corrected diurnal patterns of Ficus leaves are presented. As show in Fig. 3A (LS1) the non-corrected diel pattern shows variations up to $50 \mu \mathrm{m}$. However, the magnitude of this variation seems unlikely when compared to previous measured variations (Syvertsen and Levy, 1982; Else et al., 1995). However, after application of the temperature correction the daily variations are limited to only $10 \mu \mathrm{m}$. Nevertheless, despite the strong decrease in diel leaf thickness variation, the daily decrease and nightly increase can still be 
observed. Furthermore, the increase in leaf thickness around noon on 27 May can be explained by the applied irrigation.

In Fig. 3B the diel leaf thickness variation directly measured by LS3 describes a pattern opposite to what ecophysiologically would be expected: maximal leaf thickness values during the day and minimal at night. Application of the sensor's temperature correction resulted in a shift of the maximal leaf thickness values towards the night and reduced values during the day. Correction of LC3 shows that the influence of temperature variation can exceed the actual variation in leaf thickness. The corrected leaf thickness shows daily variations of $30 \mu \mathrm{m}$, more than double in comparison to LS1. Furthermore, no effects of irrigation are observed. This could be explained by the difference in age between the two measured leaves, by intercepting solar radiation or location of the leaf on the stem.

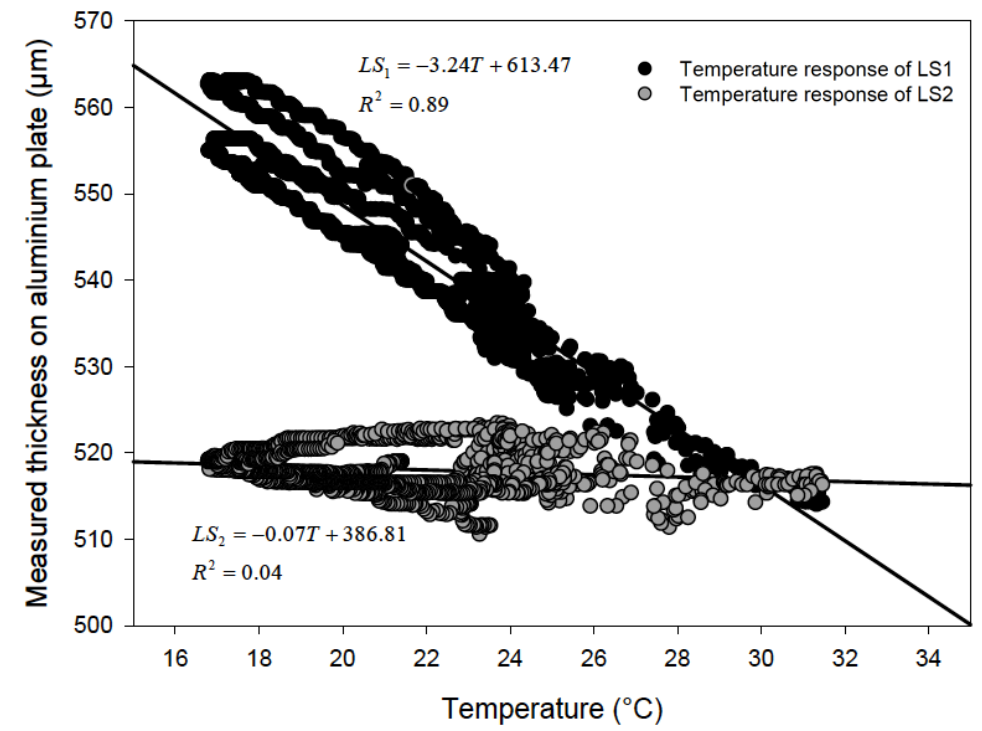

Fig. 1 Two typical temperature responses of LeafSen (LS) thickness sensors. Responses to air temperature variation were measured on an aluminium plate with assumed constant thickness in a greenhouse environment.

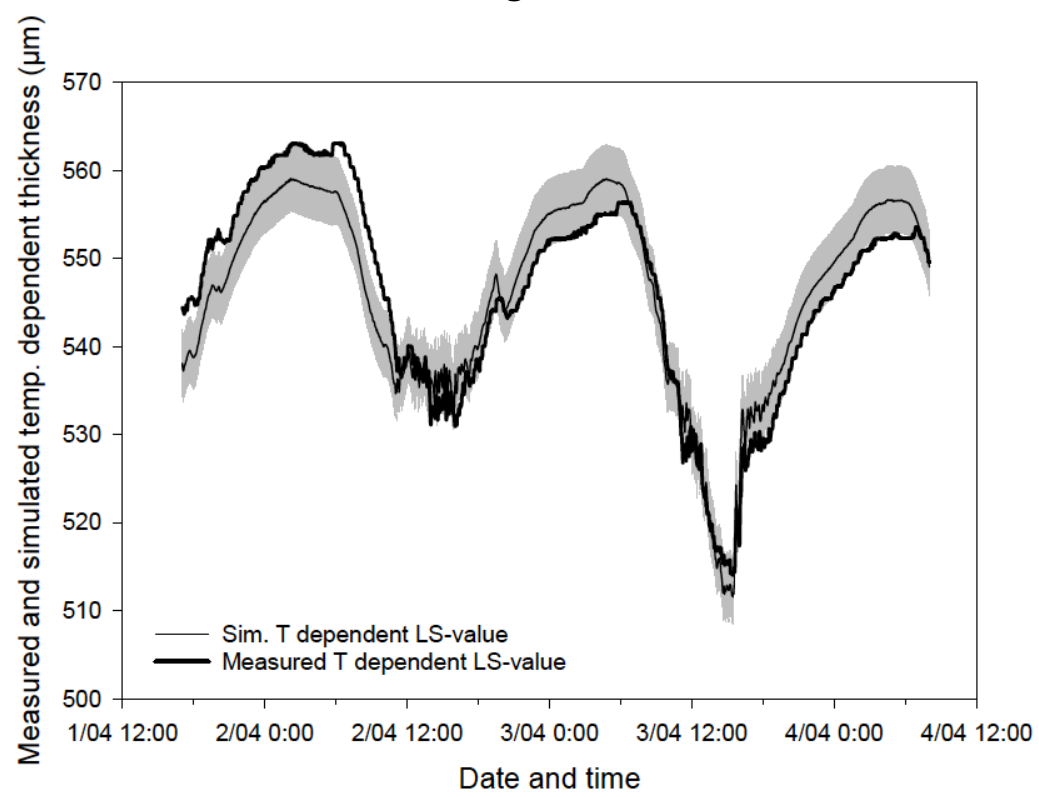

Fig. 2 Comparison of measured variation of LeafSen (LS) signals when installed on an aluminium plate and simulation of the temperature dependent signal and corresponding error bar, based on the standard error of the regression, for LS1 with use of the slope of the calculated correction curve $\left(\mathrm{LS}_{1}=-3.24 \mathrm{~T} ; \mathrm{R}^{2}=0.89\right)$. 

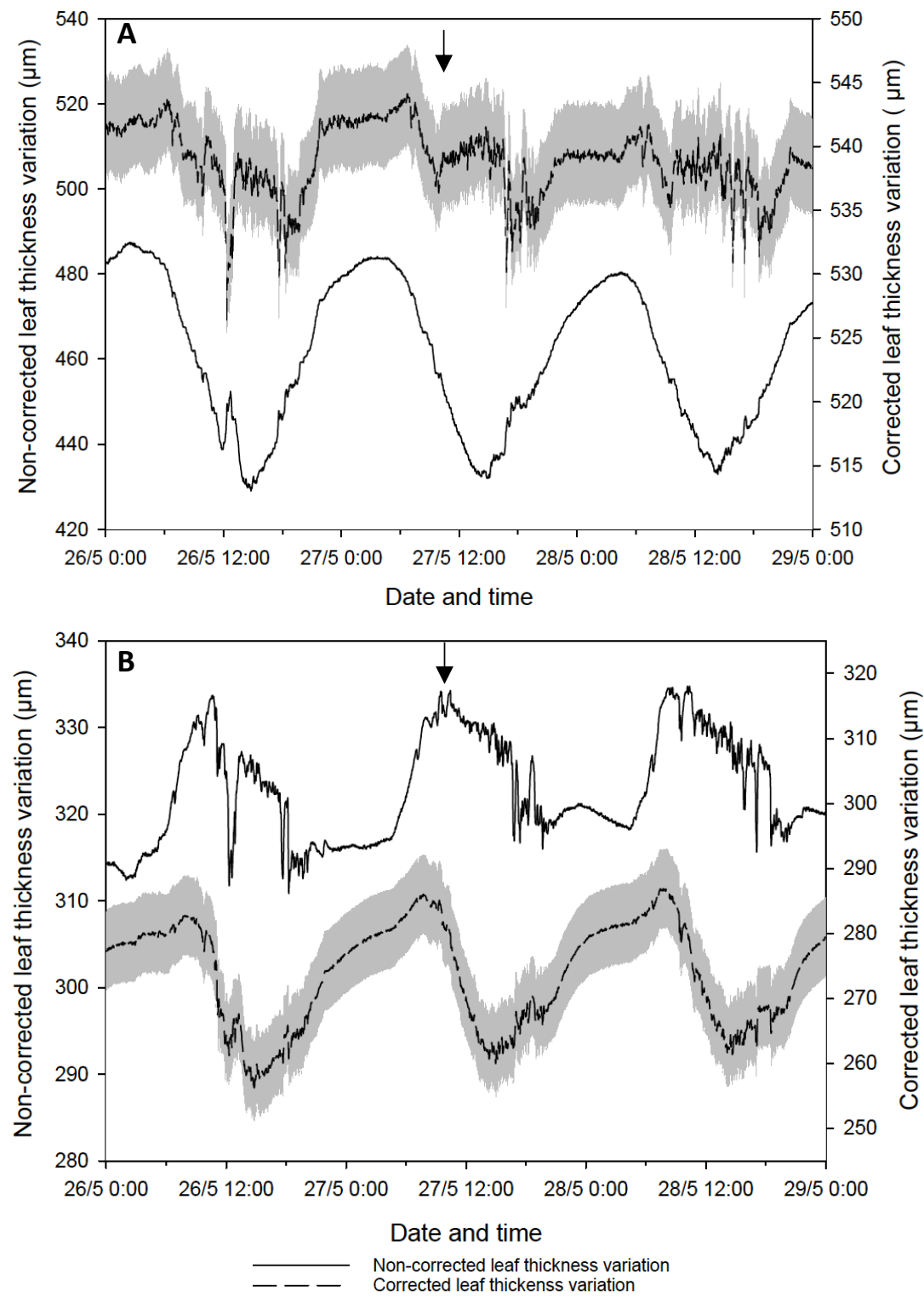

Fig. 3 Measured and corrected leaf thickness variations with error bar, based on the standard error of the regression, of Ficus benjamina in greenhouse conditions from 16 to 29 May: (A) shows the measurements before and after correction for temperature influence on sensor LS1 $\left(\mathrm{LS}_{1}=-3.24 \mathrm{~T}\right.$; $\left.\mathrm{R}^{2}=0.89\right)$; (B) represents measurements before and after temperature correction for $\mathrm{LS} 3\left(\mathrm{LS}_{3}=1.22 \mathrm{~T} ; \mathrm{R}^{2}=0.56\right)$. Moment of irrigation is indicated with an arrow.

\section{CONCLUSION}

In this study the influence of temperature on LeafSen sensors was investigated. Two types of temperature relations could be distinguished. The first sensor type showed a strong positive or negative relationship with temperature (LS1), the second type showed hardly any variation with changing temperature (LS2). A sensor specific temperature response curve is therefore recommended. Both types showed a hysteresis in LeafSen temperature dependent output to air temperature variation. It was shown that the temperature response could result in a magnification, reduction and even reversal of the physiologically expected diel pattern. Repetition of the experiment will allow determination of a possible influence of time or daily temperature range on the set slope. The corrected leaf thickness data can now be used in a leaf thickness simulation model, which can be used for assessment of the plant's water status and greenhouse climate control and irrigation scheduling. 


\section{ACKNOWLEDGEMENTS}

The authors thank the Agency for Innovation by Science and Technology in Flanders (IWT) for granting the funding of the Sense-IT LA-trajectory to Kathy Steppe, which supports the PhD funding of Fran Lauriks and Hans Van de Put. The authors are also indebted to Philip Deman, Geert Favyts and Erik Moerman for the technical support, and to Bert Schamp and the staff at PCS for the counsel and attendance of all plant material.

\section{LITERATURE CITED}

Bachmann, F. (1922). Studien über Dickenänderungen von Laubblättern. Jahrbucher fur wissenschaftliche Botanik 61, $372-429$

Búrquez, A. (1987). Leaf thickness and water deficit in plants: a tool for field studies. Journal of Experimental Botany 38 (189), 109-114.

Cirillo, C., Caputo, R., Raimondi, G., De Pascale, S. (2013). Irrigation management of ornamental shrubs under limited water resources. Paper presented at: International Symposium on New Technologies for Environment Control, Energy-Saving and Crop Production in Greenhouse and Plant Factory - Greensys (Jeju, Korea).

De Swaef, T., and Steppe, K. (2010) Linking stem diameter variations to sap flow, turgor and water potential in tomato. Functional Plant Biology 37 (5), 429-438.

De Swaef, T., Vermeulen, K., Vergote, N., Van Lommel, J., Van Labeke, M.-C., Bleyaert, P, Steppe, K. (2012). Plant Sensors help to understand Tipburn in Lettuce. Presented at: International Symposium on Horticulture in Europe (Angers, France).

Else, M.A., Davies, W.J., Malone, M., Jackson, M.B. (1995). A Negative Hydraulic Message from Oxygen-Deficient Roots of Tomato Plants?. Plant Physiology 109 (3), 1017-1024.

Heilman, M.D., Gonzalez, C.L., Swanson, W.A., Rippert, W.J. (1968). Adaptation of a Linear Transducer for Measuring Leaf Thickness. ACSESS 60 (5), 578-579.

Jones, H.G. (2004). Irrigation scheduling: advantages and pitfalls of plant-based methods. Journal of Experimental Botany 55 (407), 2427-2436.

Kadoya, K. (1978). Studies on the Hydrophysiological Rhythms of Citrus Trees. III. Effect of Soil Temperature on the Cyclic Fluctuations of Leaf Thickness. Journal of the Japanese Society for Horticultural Science 47, 167-171.

Malone, M. (1992). Kinetics of wound-induced hydraulic signals and variation potentials in wheat seedlings. Planta $187(4), 505-510$.

Meidner, H. (1952). An Instrument for the Continuous Determination of Leaf Thickness Changes in the Field. Journal of Experimental Botany 3 (3), 319-325.

Pardossi, A., Incrocci, L. (2011). Traditional and New Approaches to Irrigation Scheduling in Vegetable Crops. HortTechnology 21 (3), 309-313.

Seelig, H.-D., Stoner, R.J., Linden, J.C. (2011). Irrigation control of cowpea plants using the measurement of leaf thickness under greenhouse conditions. Irrigation Science 30 (4), 2477-257.

Sharon, Y., Bravdo, B.-A. (1996). Irrigation control for citrus according to the diurnal cycling of leaf thickness. Proceedings of the international conference on water \& irrigation, 273-283 (Tel Aviv, Israel).

Sharon Y., Bravdo, B.-A. (2001). A Fully-Automated Orchard Irrigation System Based on Continuous Monitoring of Turgor Potential with a Leaf Sensor. Paper presented at: International Symposium on Sensors in Horticulture (Haifa, Israel).

Sharon, Y., Bravdo, B.-A., Nechama, B. (2001). Aspects of the water economy of avocado trees (Persea Americana, cv. Hass). South African Avocado Growers' Association Yearbook 24, 55-59.

Steppe, K., De Pauw, D.J., Lemeur, R., and Vanrolleghem, P.A. (2006) A mathematical model linking tree sap flow dynamics to daily stem diameter fluctuations and radial stem growth. Tree Physiology 26 (3), 257-273.

Steppe, K., De Pauw, J.W.D., Lemeur, R. (2008). A step towards new irrigation scheduling strategies using plant-based measurements and mathematical modelling. Irrigation Science 26, 505-517. 
Syvertsen, J.P., Levy, Y. (1982). Diurnal Changes in Citrus Leaf Thickness, Leaf Water Potential and Leaf to Air Temperature Difference. Journal of Experimental Botany 33 (4), 783-789.

Vanhassel, P., Bleyaert, P., Van Lommel, J., Vandevelde, I., Crappé, S., Van Hese, N., Hanssens, J., Steppe, K., Van Labeke, M.-C. (2014). Rise of nightly air humidity as a measure for tipburn prevention in hydroponic cultivation of butterhead lettuce. Presented at: International Horticultural Congress on Horticulture: Sustaining Lives, Livelihoods and Landscapes (IHC2014): International Symposium on Innovation and New Technologies in Protected Cropping (Brisbane, Australia). 